\title{
EDITORIAL
}

\section{Unburying the Facts about Avalanche Victim Pathophysiology}

The last decade has witnessed an emerging medical literature employing more rigorous scientific approaches to the study of avalanche victim pathophysiology as dedicated investigators have rapidly advanced this area of research into a well-developed field of wilderness medicine. The scant literature available before this period was based primarily on anecdotal field observations, with a minimum number of well-designed, evidencebased studies of the human condition associated with snow burial or the pathophysiology of death during avalanche accidents.

Ten years ago, when addressing groups of junior ski patrollers and avalanche science students, my question regarding the leading cause of death in recreational avalanche accidents was invariably answered with "trauma." Clearly the response was a reasonable, although incorrect, assumption based upon instinctive understanding regarding the remarkable forces involved in these events, but not on concrete evidence. The question was even more important than I appreciated at the time, as new survival devices that either prevented burial or prolonged the time to asphyxiation after burial were being studied and perfected.

Avalanche professionals and rescue personnel have long appreciated that asphyxiation was the mechanism of death in roughly two thirds of avalanche victims. The early studies supporting this statistical dogma were primarily reported in foreign journals and included either small numbers of victims or vague methodologies that combined data from multiple countries. ${ }^{1-5}$ Two subsequent studies utilizing firm scientific methods attempting to elucidate an answer appeared in English journals. ${ }^{6,7}$

In 1989, Stalsberg et $\mathrm{al}^{6}$ published an autopsy series from North Norway including 12 victims from 2 large avalanche accidents involving an unusually dense maritime snowpack. Their controversial conclusion, based partly on the common finding of pulmonary and cerebral edema in addition to low aortic oxygen pressures, was that the primary mechanism of death was generalized tissue compression from the weight of the snow, followed consequently by acute respiratory and circulatory collapse. The concept of chest restriction and generalized body compression from the weight of the consoli- dated snow gained considerable acceptance and was a frequent topic of discussion among experts in the European avalanche community. However, this study could be criticized as suffering from a mechanistic bias in these victims based on the unusual circumstances surrounding the dense snow conditions, in addition to alternative explanations of their findings, such as primary asphyxiation.

Also in 1989, Grossman et $\mathrm{al}^{7}$ retrospectively analyzed 12 deaths reported to the Utah Avalanche Forecast Center over the period extending from 1982 to 1987. The study represented the first report on the medical aspects of avalanche injury and death in the United States. Lethal trauma was concluded as the primary cause of death in only $2(16 \%)$ of the victims, supporting asphyxiation $(83 \%)$ as the predominant mechanism of death. Unfortunately, although both of these studies attempted to use more precise scientific methodologies, they were plagued by small numbers or unusual conditions, and meaningful conclusions could not be drawn, other than that asphyxiation played a dominant role in these deaths.

The hallmark paper by Falk et al, ${ }^{8}$ based on the extensive Swiss experience, identified distinct stages of death in the survival curve and further stressed the need for continued higher-quality academic research targeted at enhancing survival and developing a better understanding of the mechanism of asphyxiation and the seemingly life-saving air pocket.

These early studies opened the door to a new decade of enthusiastic investigation of the physiology of snow burial and an improved understanding of the pathophysiology during avalanche death. The findings from more recent work on fatality mechanisms and the physiology of asphyxiation in snow have reinforced the potential impact on revisiting current survival techniques and the development of devices focused on burial prevention or prolonging survival after burial. ${ }^{9-11}$

The previous issue of Wilderness and Environmental Medicine, McIntosh et $\mathrm{al}^{12}$ reexamined the mechanism of avalanche death by retrospectively studying 56 avalanche fatalities in Utah from 1989 to 2006 using an autopsy analysis of medical examiner records. Their 
conclusions are based on circumstances surrounding the accidents as well as physical evidence revealed during the autopsies, whether internal or external, performed on a case-by-case basis, as decided by the medical examiner. Similar to previous mechanistic analyses assessed by autopsy (the presumed gold standard), causes were categorized as asphyxiation, trauma, combined asphyxiation and trauma, or hypothermia. A surprisingly low $5.4 \%$ of deaths were determined to be related to trauma alone, while $8.9 \%$ were due to combined trauma and asphyxia. A total of $85.7 \%$ of the victims were felt to have succumbed to asphyxiation. No hypothermic deaths were reported.

Although these percentages are comparable to those of other smaller series reported previously in the international literature, there remains an unanswered variability among some of the larger series from Europe, which leaves us questioning the ability to extrapolate these results outside of Utah. There is no doubt that some of these discrepancies can be based in methodological differences and a high percentage of deaths categorized as "other" or "unknown" in the older studies. However, these differences loudly beg the possibility that variables such as backcountry topographic inconsistencies throughout the world have an impact on potential trauma. For example, a high density of forested terrain, crevasses, rocks, or cliff bands might favor trauma, whereas open bowls, terrain-traps, and above-tree-line areas could favor asphyxiation. Such an important variable, which the authors briefly consider, could possibly dictate regional frequencies of traumatic deaths.

This important consideration is further complicated by the prevalent use, over the last 15 years, of the avalanche air bag system (ABS, Peter Aschauer, Gräfelfing, Germany) in Europe. This device has proved itself effective at preventing full burial while aiding in rapid localization, although it has no role in preventing traumatic injury.

One of the largest recent analyses of avalanche deaths was reported by Tschirky et $\mathrm{al}^{13}$ from the Swiss Federation for the Study of Snow and Avalanche (SNF). Surprisingly, these authors described a $43 \%$ incidence of traumatic death in a total of 91 victims during a 10-year period in Switzerland. Although the methodology concluding the cause of death is not entirely clear in the paper, the SNF is the primary research and reporting institute in Switzerland, where physicians are typically included in the first-response team at accident scenes. It is entirely possible that the widespread use of the ABS in Switzerland has shifted the mechanism of death during this period in favor of trauma. If this is true, improved primary prevention aimed at head trauma could save additional lives, since traumatic brain injury has been shown to be a leading cause of death by trauma. ${ }^{14}$

However, the authors of another recent autopsy study ${ }^{15}$ from the Medical University Innsbruck in Austria retrospectively reviewed the pattern and severity of injury and death in avalanche victims. A total of 36 deaths occurring between 1996 and 2005 were evaluated at this regional level 1 trauma center, which serves several backcountry areas in the Austrian Alps. Only 2 victims $(5.6 \%)$ suffered lethal traumatic injury (cervical spine fracture and dislocation), while $91.7 \%$ of victims were determined to have died from asphyxia, further supporting significant regional variability even within European alpine countries. Interestingly, review of the reported 106 cases in which the ABS has been deployed during avalanche accidents over the last 15 years reveals no significant difference in usage between these countries. ${ }^{16}$

In fact, the European avalanche community has long believed that evolving survival technologies should concentrate on preventing burial, thereby avoiding asphyxiation, while understanding that traumatic death may not be avoidable. In the United States, however, survival tactics have concentrated on prevention of asphyxiation after burial has occurred. The Avalung breathing device (Black Diamond Equipment Ltd, Salt Lake City, UT) has gained some popularity among backcountry enthusiasts and avalanche professionals and has probably saved lives. Physiologic research during experimental avalanche burial simulation has proved its potential lifesaving effect; the device slows hypercapnic asphyxiation. ${ }^{9}$ Unfortunately, the Avalung remains a new device with a short track record compared to the ABS. Its widespread use and acceptance has been a slow process as the device has evolved into user-friendly equipment in its present form, incorporated into a backpack. In order to realize the full potential of this device for reducing death by asphyxiation, several years of analysis with increased usage of the device will be required. However, regardless of the survival devices' effectiveness at either preventing burial or rapid asphyxiation, traumatic death remains an important unresolved issue requiring further study.

The paper by McIntosh and colleagues is a well-performed, well-designed analysis for this type of work and contributes to our understanding of the pathogenesis during avalanche death, specifically in Utah. However, the data should be interpreted cautiously and should not be readily extrapolated to other avalanche terrain throughout the world. These results, along with future prospective investigations worldwide, will hopefully reveal any differences in the cause of avalanche death based upon topographic, device-related, or other unknown variables. 


\section{References}

1. Lapras A. Pathologie des ensevelis. Nouv Presse Med. 1980;9:3124-3130.

2. Eliakis E. La mort violente par avalanche. Mise au point medico-legale. Med Legale Dommage Corporel. 1974;7: 83-87.

3. Lugger L, Unterdorfer H. Obduktionsergebnisse bei Lawinenverunfallten. Artztliche Prax. 1972;24:28-31.

4. Markwalder D. Medizinische Aspekte bei Lawinenunfallen. Zurich: Druck AG; 1969.

5. Valla F. Neige et Avalanches, 1976-1986. Grenoble, France: Association Nationale Pour L'Etude de la Neige et des Avalanches; 1987.

6. Stalsberg H, Albretsen C, Gilbert M, et al. Mechanisms of death in avalanche victims. Virchows Arch Pathol Anat. 1989;414:415-422.

7. Grossman MD, Saffle JR, Thomas F, Tremper B. Avalanche trauma. J Trauma. 1989;29:1705-1709.

8. Falk M, Brugger H, Adler-Kastner L. Avalanche survival chances. Nature. 1994;368:21.

9. Grissom CK, Radwin MI, Harmston $\mathrm{CH}$, et al. Respiration during snow burial using an artificial air pocket. JAMA. 2000;283:2266-2271.

10. Radwin MI, Grissom CK, Scholand MB, Harmston CH. Normal oxygenation and ventilation during snow burial by the exclusion of exhaled carbon dioxide. Wilderness Environ Med. 2001;12:256-262.

11. Brugger H, Sumann G, Meister R, et al. Hypoxia and hypercapnia during respiration into an artificial air pocket in snow: implications for avalanche survival. Resuscitation. 2003;59:81-88.

12. McIntosh SE, Grissom CK, Olivares CR, Kim HS, Tremper B. Cause of death in avalanche fatalities. Wilderness Environ Med. 2007;18:293-297.

13. Tschirky F, Brabec B, Kern M. Avalanche rescue devices, state of the development, success and failure [in German]. In: Osterreichische Gesellschaft fur Alpin und Hohenmedizin. Austrian Society of Mountain Medicine; 2001:101125 .

14. Johnson SM, Johnson AC, Barton RG. Avalanche trauma and closed head injury: adding insult to injury. Wilderness Environ Med. 2001;12:244-247.

15. Hohlrieder M, Brugger H, Schubert H, et al. Pattern and severity of injury in avalanche victims. High Alt Med Biol. 2007;8:56-61.

16. Swiss Foundation for the Study of Snow and Avalanche. Available at: http://www.abssystem.com/abs-Dateien/facts/ reality.htm. Accessed June 14, 2007.

Martin I. Radwin, MD Salt Lake City, UT 